Viet Hildebrand | André Laschewsky | Erik Wischerhoff

\title{
Modulating the solubility of zwitterionic poly((3-methacrylamidopropyl) ammonioalkane sulfonate)s in water and aqueous salt solutions via the spacer group separating the cationic and the anionic moieties
}

Suggested citation referring to the original publication:

Polymer Chemistry 7 (2016), pp. 731-740

DOI http://dx.doi.org/10.1039/c5py01642h

ISSN (online) 1759-9962

ISSN (print) 1759-9954

Postprint archived at the Institutional Repository of the Potsdam University in:

Postprints der Universität Potsdam

Mathematisch-Naturwissenschaftliche Reihe ; 309

ISSN 1866-8372

http://nbn-resolving.de/urn:nbn:de:kobv:517-opus4-103040 


group separating the cationic and the anionic moieties $\uparrow$

\begin{abstract}
Viet Hildebrand, ${ }^{a}$ André Laschewsky*a,b and Erik Wischerhoff ${ }^{\mathrm{b}}$
Complementary to the well-established zwitterionic monomer 3-((3-methacrylamidopropyl)dimethylammonio)propane-1-sulfonate (SPP), the closely related monomers 2-hydroxy-3-((3-methacrylamidopropyl)dimethylammonio)propane-1-sulfonate (SHPP) and 4-((3-methacrylamidopropyl)dimethylammonio)butane-1-sulfonate (SBP) were synthesised and polymerised by reversible addition-fragmentation chain transfer (RAFT) polymerisation, using a fluorophore labeled RAFT agent. The polyzwitterions of systematically varied molar masses were characterised with respect to their solubility in water and aqueous salt solutions. Both poly(sulfobetaine)s show thermoresponsive behaviour in water, exhibiting phase separation at low temperatures and upper critical solution temperatures (UCST). For both polySHPP and polySBP, cloud points depend notably on the molar mass, and are much higher in $\mathrm{D}_{2} \mathrm{O}$ than in $\mathrm{H}_{2} \mathrm{O}$. Also, the cloud points are effectively modulated by the addition of salts. The individual effects can be in parts correlated to the Hofmeister series for the anions studied. Still, they depend in a complex way on the concentration and the nature of the added electrolytes, on the one hand, and on the detailed nature of the spacer group separating the anionic and the cationic charges of the betaine moiety, on the other hand. As anticipated, the cloud points of polySBP are much higher than the ones of the analogous polySPP of identical molar mass. Surprisingly, the cloud points of polySHPP are also somewhat higher than the ones of their polySPP analogues, despite the additional hydrophilic hydroxyl group present in the spacer separating the ammonium and the sulfonate moieties. These findings point to a complicated interplay of the various hydrophilic components in polyzwitterions with respect to their overall hydrophilicity. Thus, the spacer group in the betaine moiety proves to be an effective additional molecular design parameter, apparently small variations of which strongly influence the phase behaviour of the polyzwitterions in specific aqueous environments.
\end{abstract}

Received 9th October 2015, Accepted 24th November 2015

DOI: $10.1039 / \mathrm{c5py} 01642 \mathrm{~h}$

www.rsc.org/polymers

\section{Introduction}

Starting in the 1980 s, zwitterionic polymers ${ }^{1-3}$ have increasingly been recognised as materials of choice to confer good biotolerance, extremely low friction and/or ultralow-fouling behaviour to surfaces. ${ }^{4-7}$ Therefore, polyzwitterions are intensely

\footnotetext{
${ }^{a}$ Institut für Chemie, Universität Potsdam, Karl-Liebknechtstr. 24-25, 14476 Potsdam-Golm, Germany. E-mail: laschews@uni-potsdam.de

${ }^{b}$ Fraunhofer Institute for Applied Polymer Research IAP, Geiselbergstr. 69, 14476 Potsdam-Golm, Germany

$\dagger$ Electronic supplementary information (ESI) available: Turbidimetric studies of aqueous solutions of polymers in $\mathrm{H}_{2} \mathrm{O}$ and $\mathrm{D}_{2} \mathrm{O}$, and the evolution of the cloud points of polySPP, polySBP, and polySHPP in 5 aqueous solutions containing inorganic salts. See DOI: 10.1039/c5py01642h
}

explored for uses in biomaterials. Moreover, by virtue of the delicate balance of attractive or repulsive interactions between the numerous charged groups themselves and with water, zwitterionic polymers often display cloud points in aqueous media with an upper critical solution temperature (UCST), or occasionally, a lower critical solution temperature (LCST) behaviour, and thus have been employed in the design of responsive polymer systems. ${ }^{8-13}$

Amidst the three main families of polyzwitterions, namely polymeric phosphobetaines, carboxybetaines, and sulfobetaines, ${ }^{1,3}$ the latter are chemically the most inert and exhibit a zwitterionic character over the broadest $\mathrm{pH}$ window (typically 2-14 minimum). Such poly(sulfobetaine)s are most conveniently prepared via free radical polymerisation. However, only a few sulfobetaine monomers suited for free 
radical polymerisation are readily available commercially at present, the most popular being 3-((2-methacryloyloxyethyl) dimethylammonio)propane-1-sulfonate ("SPE") and 3-((3methacrylamidopropyl)dimethylammonio)propane-1-sulfonate ("SPP"). Out of these, the latter seems to provide the best combination of polymerizability, hydrophilicity and resistance to hydrolysis. Therefore, we recently synthesised polySPP with well-defined molar masses, low polymer dispersity indexes, and defined end groups by reversible-addition-fragmentation chain transfer (RAFT) polymerisation, and studied its aqueous phase behaviour in the absence and presence of various low molar mass salts. ${ }^{14}$ In addition to a notable molar mass effect and a moderate end group effect on the cloud point, we observed a strong and complex influence of added low molar mass electrolytes on the solubility. Characteristically, these effects depend sensitively on the amount as well as on the chemical nature of the salt added. Also, the cloud point passed through a - so far not yet understood - maximum with increasing concentrations of a given salt, in agreement with occasional earlier reports on the aqueous solution behaviour of other poly(ammoniopropanesulfonate)s. ${ }^{15,16}$ Furthermore, and in contrast to the effect on the LCST of water-soluble polymers, we observed a marked H-D isotope effect for polySPP, which exhibits markedly increased cloud points in $\mathrm{D}_{2} \mathrm{O}$ compared to those in $\mathrm{H}_{2} \mathrm{O}{ }^{14}$

With the aim to modulate the accessible range of cloud points of polySPP, we have extended our previous studies by synthesising and studying two poly(sulfobetaine)s, which differ from polySPP in their chemical structure, by varying the hydrophilicity of the spacer group that separates the ammonium and the sulfonate moieties. Such spacer variations in polyzwitterions have been rare up to now. ${ }^{17-22}$ On the one hand, we extended the spacer group by one methylene group, thus creating poly( $N, N$-dimethyl- $N$-(3-methacrylamidopropyl)ammoniobutanesulfonate) (polySBP). On the other hand, we added one hydroxyl group to the spacer group, thus creating poly( $N, N$-dimethyl- $N$-(3-methacrylamidopropyl)ammonio-2-hydroxypropanesulfonate) (polySHPP). On the basis of the inherent hydrophilicity of the hydroxyl group and of the inherent hydrophobicity of the methylene group, we expected polySHPP to be somewhat more hydrophilic, and polySBP to be somewhat more hydrophobic than the reference compound polySPP. This should presumably induce a decrease or increase, respectively, of the UCST-type cloud points. The two underlying monomers SBP and SHPP are accessible by alkylation of the commercial precursor monomer $3-\mathrm{N}, \mathrm{N}$-dimethylaminopropyl methacrylamide, but have been hardly described so far. In fact, polySHPP has been only claimed in the patent literature ${ }^{23}$ except for one report, which did not disclose synthetic or analytical structural information on the polymer or its monomer. ${ }^{17}$ Moreover, the context of the sparse discussion suggests that the polySHPP samples studied were partially hydrolyzed $^{24}$ and thus presented de facto copolymers of SHPP with methacrylic acid. Concerning polySBP, the synthesis of monomer SBP was reported most recently during our ongoing studies, ${ }^{21}$ whereas its polymerisation and polymer properties were not described.

\section{Experimental part}

\section{Materials}

General chemicals and solvents. $N$-(3-Dimethylaminopropyl)methacrylamide (DMAPMA, kindly donated by Evonik Industries, Germany), butane sultone (Acros, 99+\%), 3-chloro2-hydroxy-1-propane sulfonic acid sodium-salt (CHPSNa, 95\%, kindly donated by Raschig), 2,6-di-tert-butyl-4-methylphenol (BHT, Fluka, >99\%), hydroquinone (Fluka, >99\%), 4,4'-azobis (4-cyanopentanoic acid) (V501, Wako, 84\%), potassium iodide (VK Labor, 99.5\%), sodium chloride ( $\mathrm{NaCl}$, ChemSolute, 99\%), ethyl acetate (Merck, 99.5\%), acetonitrile (Sigma Aldrich, 99.8\%), trifluoroethanol (TFE, Roth, 99.8\%), methanol (Chemievertrieb Magdeburg, 99\%), ethanol (J. T. Baker, 99.9\%), Amberlite Mixed Bed Exchanger Amberlite MB-150 (Sigma Aldrich), and $\mathrm{D}_{2} \mathrm{O}$ (Armar, 99.9 atom\% D) were used as received. The fluorophore-labelled chain transfer agent $(R)-2$ (6-(dimethylamino)-1,3-dioxo-1H-benzo[de]isoquinolin-2 $(3 H)$ yl)ethyl 4-cyano-4-(((phenethylthio)carbonothioyl)thio)pentanoate (CTA) was synthesised as described previously. ${ }^{14}$ Deionised water was additionally purified by using a Millipore Milli-Q Plus water purification system (resistivity $18 \mathrm{M} \Omega \mathrm{cm}^{-1}$ ).

Synthesis of 2-hydroxy-3-((3-methacrylamidopropyl)dimethylammonio)propane-1-sulfonate (SHPP). $\mathrm{N}$-(3-Dimethylaminopropyl)methacrylamide (DMAPMA, $1.72 \mathrm{~g}, 0.01 \mathrm{~mol}$ ), 3-chloro-2-hydroxy-1-propane sulfonic acid sodium-salt (CHPSNa, $1.97 \mathrm{~g}, 0.01 \mathrm{~mol}$ ), potassium iodide (0.02 g, $1 \mathrm{~mol}$ $\%)$, and a few milligrams of 2,6-di-tert-butyl-4-methylphenol (BHT) are dissolved in a mixture of ethanol $(7 \mathrm{ml})$ and water (3 ml). After purging with $\mathrm{N}_{2}$, the mixture $(\mathrm{pH}=9)$ is refluxed while stirring for 4 days. After cooling, water $(50 \mathrm{ml})$ is added to the mixture, resulting in a white precipitate which is removed by filtration. The filtrate is passed through a column filled with a mixed bed ion exchanger (capacity: $0.55 \mathrm{meq} \mathrm{ml}^{-1}$ ), a small scale of hydroquinone is added, and the solution is freeze-dried. Crystallisation of the residue from acetonitrile yields monomer 2-hydroxy-3-((3-methacrylamidopropyl)dimethylammonio)propane-1-sulfonate as a colourless powder (yield $2.4 \mathrm{~g}, 77 \%$ ).

${ }^{1} \mathrm{H}$ NMR $\left(300 \mathrm{MHz}, \mathrm{D}_{2} \mathrm{O}, 298 \mathrm{~K}\right): \delta(\mathrm{ppm})=1.94(\mathrm{~s}, 3 \mathrm{H},-\mathrm{C}-$ $\mathrm{CH}_{3}$ ), $2.09\left(\mathrm{~m}, 2 \mathrm{H},-\mathrm{CON}-\mathrm{C}-\mathrm{CH}_{2}-\right), 3.15(\mathrm{~d}, 2 \mathrm{H}, J=5.7 \mathrm{~Hz}$, $\left.-\mathrm{CH}_{2}-\mathrm{SO}_{3}\right), 3.2\left(\mathrm{~s}, 6 \mathrm{H},-\mathrm{N}^{+}\left(\mathrm{CH}_{3}\right)_{2}\right), 3.38(\mathrm{t}, 2 \mathrm{H}, J=6.5 \mathrm{~Hz},-\mathrm{CON}-$ $\mathrm{CH}_{2}{ }^{-}$), 3.4-3.7 (m, 4H, $-\mathrm{CH}_{2}-\mathrm{N}^{+}-\mathrm{CH}_{2}-$ ), 4.66 (m, $\left.1 \mathrm{H},-\mathrm{CH}-\mathrm{OH}\right)$, (s, $1 \mathrm{H}, \mathrm{CH}=\mathrm{C}-\mathrm{CON}-($ cis $)), 5.72(\mathrm{~s}, 1 \mathrm{H}, \mathrm{CH}=\mathrm{C}-\mathrm{CON}-($ trans $))$.

${ }^{13} \mathrm{C} \mathrm{NMR}\left(75 \mathrm{MHz}, \mathrm{D}_{2} \mathrm{O}, 298 \mathrm{~K}\right): \delta(\mathrm{ppm})=18.0\left(-\mathrm{CH}_{3}\right), 22.8$ $\left(-\mathrm{CON}-\mathrm{C}-\underline{\mathrm{CH}}_{2}-\right), 36.6\left(-\mathrm{CON}-\underline{\mathrm{CH}}_{2}-\right), 52.2\left(-\mathrm{N}^{+}\left(\underline{\mathrm{CH}}_{3}\right)_{2}\right), 55.6$ $\left(-\mathrm{CH}_{2}-\mathrm{SO}_{3}\right), 63.1(-\mathrm{CH}-\mathrm{OH}), 63.8\left(-{ }_{-} \mathrm{CH}_{2}-\mathrm{N}^{+}-\right), 67.4\left(-\mathrm{N}^{+}-\underline{C H}_{2}-\right.$ $\mathrm{CHOH}-$ ), 121.7 (= $\underline{\mathrm{CH}}_{2}$ ), 139.3 (= $\underline{\mathrm{C}}-\overline{\mathrm{CON}}-$ ), 172.4 (-ㅁN-).

Mass spectrum (HR-MS, ESI): calculated: $309.148[\mathrm{M}+\mathrm{H}]^{+}$; found: $309.148[\mathrm{M}+\mathrm{H}]^{+}$.

Elemental analysis $\left(\mathrm{C}_{12} \mathrm{H}_{24} \mathrm{~N}_{2} \mathrm{O}_{5} \mathrm{~S}, M_{\mathrm{r}}=308.39\right)$ : Calcd: $\mathrm{C}=$ $46.74 \%, \mathrm{H}=7.84 \%, \mathrm{~N}=9.08 \%, \mathrm{~S}=10.40 \%$; found: $\mathrm{C}=$ $46.55 \%, \mathrm{H}=7.90 \%, \mathrm{~N}=9.10 \%, \mathrm{~S}=10.22 \%$.

FT-IR (selected bands, $\left.\mathrm{cm}^{-1}\right): 3340 \nu(\mathrm{OH}), 3020 \nu\left(\mathrm{N}^{+}-\mathrm{CH}_{3}\right)$, $2933 \nu\left(\mathrm{CH}_{2}\right), 1658 \nu$ (amide I), $1617 \nu(\mathrm{C}=\mathrm{C}), 1537 \nu$ (amide II), $1201 \nu_{\mathrm{as}}\left(\mathrm{SO}_{3}\right), 1040 \nu_{\mathrm{s}}\left(\mathrm{SO}_{3}\right)$. 
Synthesis of 4-((3-methacrylamidopropyl)dimethylammonio) butane-1-sulfonate (SBP). $N$-(3-Dimethylaminopropyl)methacrylamide (DMAPMA, $85.3 \mathrm{~g}, 0.50 \mathrm{~mol}$ ) and butane sultone $\left(56 \mathrm{ml}, \rho=1.331 \mathrm{~g} \mathrm{ml}^{-1}, 0.55 \mathrm{~mol}\right)$ in acetonitrile $(50 \mathrm{ml})$ are stirred at room temperature. After $1 \mathrm{~h}$, a white solid begins to precipitate. After another $9 \mathrm{~h}$ of reaction, the precipitate is filtered off, washed with dry ethyl acetate, collected and dried in vacuo, to give the pure monomer 4-((3-methacrylamidopropyl)dimethylammonio)butane-1-sulfonate as a colourless powder (yield $142 \mathrm{~g}, 93 \%$ ).

${ }^{1} \mathrm{H}$ NMR $\left(300 \mathrm{MHz}, \mathrm{D}_{2} \mathrm{O}, 298 \mathrm{~K}\right): \delta(\mathrm{ppm})=1.82-2.08(\mathrm{~m}$, $\left.9 \mathrm{H},-\mathrm{CH}_{2}-\mathrm{C}-\mathrm{SO}_{3},-\mathrm{N}^{+}-\mathrm{C}-\mathrm{CH}_{2}-,=\mathrm{C}-\mathrm{CH}_{3},-\mathrm{CON}-\mathrm{C}-\mathrm{CH}_{2}-\right), 2.99$ $\left(\mathrm{t}, J=7.3 \mathrm{~Hz}, 2 \mathrm{H},-\mathrm{CH}_{2}-\mathrm{SO}_{3}\right), 3.1\left(\mathrm{~s}, 6 \mathrm{H},-\mathrm{N}^{+}\left(\mathrm{CH}_{3}\right)_{2}\right), 3.3-3.4$ $\left(\mathrm{m}, 6 \mathrm{H},-\mathrm{CON}-\mathrm{CH}_{2}-\right.$ and $\left.-\mathrm{CH}_{2}-\mathrm{N}^{+}-\mathrm{CH}_{2}-\right), 5.51$ (s, $1 \mathrm{H}$, $\mathrm{CH}=\mathrm{C}-\mathrm{CON}-$ cis $), 5.74(\mathrm{~s}, 1 \mathrm{H}, \mathrm{CH}=\mathrm{C}-\mathrm{CON}-$ trans $) .{ }^{13} \mathrm{C} \mathrm{NMR}$ $\left(75 \mathrm{MHz}, \mathrm{D}_{2} \mathrm{O}, 298 \mathrm{~K}\right): \delta(\mathrm{ppm})=19.2\left(-\mathrm{CH}_{3}\right), 22.4$ and 22.6 $\left(-\mathrm{N}^{+}-\mathrm{C}-\mathrm{CH}_{2}-\mathrm{CH}_{2}-\right), 23.8\left(-\mathrm{CON}-\mathrm{C}-\underline{\mathrm{CH}}_{2}{ }^{-}\right), 37.8\left(-\mathrm{CON}^{-} \mathrm{CH}_{2}-\right)$, $51.5\left(-\mathrm{CH}_{2}-\mathrm{SO}_{3}\right), 52.3\left(-\mathrm{N}^{+}\left(\underline{\mathrm{CH}}_{3}\right)_{2}\right), 63.3\left(-\mathrm{CH}_{2}-\mathrm{N}^{+}-\right), 64.9\left(-\mathrm{N}^{+}-\right.$ $\left.\mathrm{CH}_{2}-\right), 122.9\left(=\underline{\mathrm{CH}}_{2}\right), 140.4(=\underline{\mathrm{C}}-\mathrm{CON}-), 173.5(-\underline{\mathrm{CON}}-)$.

Mass spectrum (HR-MS, ESI): calculated: $307.168[\mathrm{M}+\mathrm{H}]^{+}$; found: $307.168[\mathrm{M}+\mathrm{H}]^{+}$.

Elemental analysis $\left(\mathrm{C}_{13} \mathrm{H}_{26} \mathrm{~N}_{2} \mathrm{O}_{4} \mathrm{~S}, M_{\mathrm{r}}=306.42\right)$. Calcd: $\mathrm{C}=$ $50.96 \%, \mathrm{H}=8.55 \%, \mathrm{~N}=9.14 \%, \mathrm{~S}=10.46 \%$; found: $\mathrm{C}=$ $50.73 \%, \mathrm{H}=8.52 \%, \mathrm{~N}=9.02 \%, \mathrm{~S}=10.51 \%$.

FT-IR (selected bands, $\left.\mathrm{cm}^{-1}\right): 3487 \nu(\mathrm{NH}), 3020 \nu\left(\mathrm{N}^{+}-\mathrm{CH}_{3}\right)$, $2933 \nu\left(\mathrm{CH}_{2}\right), 1655 \nu$ (amide I), $1605 \nu(\mathrm{C}=\mathrm{C}), 1546 \nu$ (amide II), $1194 \nu_{\text {as }}\left(\mathrm{SO}_{3}\right), 1042 \nu_{\mathrm{s}}\left(\mathrm{SO}_{3}\right)$.

Synthesis of poly(2-hydroxy-3-((3-methacrylamidopropyl)dimethylammonio)propane-1-sulfonate), poly(SHPP). In a typical procedure, 2-hydroxy-3-((3-methacrylamidopropyl)dimethylammonio)propane-1-sulfonate (SHPP, $5.0 \mathrm{~g}, 1.7 \times 10^{-2}$ mol), $\quad(R)$-2-(6-(dimethylamino)-1,3-dioxo-1H-benzo[de]isoquinolin-2(3H)-yl)ethyl 4-cyano-4-(((phenethylthio)carbonothioyl)thio)pentanoate (CTA, $0.017 \mathrm{~g}, 2.8 \times 10^{-5} \mathrm{~mol}$ ), and 4,4'-azobis(4-cyanopentanoic acid) (V501, $0.002 \mathrm{~g}, 6 \times 10^{-6} \mathrm{~mol}$ ) are dissolved in trifluoroethanol $(2 \mathrm{ml})$. After purging with $\mathrm{N}_{2}$ for $30 \mathrm{~min}$, the yellow solution is polymerised at $75{ }^{\circ} \mathrm{C}$ for $18 \mathrm{~h}$. Then, the mixture is cooled and precipitated into methanol (repeated 3 times). The polymer is isolated and dried in vacuo. Homopolymer polysHPP is obtained as a hygroscopic, amorphous yellow solid (yield $3.0 \mathrm{~g}, 60 \%)$.

The individual samples are named polySHPP $_{n}$, with $n$ being the number average degree of polymerisation that was theoretically calculated (see Table 2).

${ }^{1} \mathrm{H}$ NMR $\left(300 \mathrm{MHz}\right.$, in dilute aqueous $\mathrm{NaCl}\left(0.9 \mathrm{~g} \mathrm{~L}^{-1}\right.$ in $\left.\left.\mathrm{D}_{2} \mathrm{O}\right), 298 \mathrm{~K}\right): \delta(\mathrm{ppm})=0.6-1.1\left(2 \mathrm{H},-\mathrm{CH}_{2}-\right.$ on/in backbone $)$, 1.6-2.1 $\left(5 \mathrm{H},-\mathrm{CH}_{3}\right.$ and $\left.-\mathrm{CON}-\mathrm{C}-\mathrm{CH}_{2}-\mathrm{C}-\right), 2.8-3.7(14 \mathrm{H},-\mathrm{CON}-$ $\left.\mathrm{CH}_{2}-\mathrm{C}-\mathrm{CH}_{2}-\mathrm{N}^{+}\left(\mathrm{CH}_{3}\right)_{2}-\mathrm{CH}_{2}-\mathrm{C}-\mathrm{CH}_{2}-\mathrm{SO}_{3}\right), 4.5-4.6 \quad(1 \mathrm{H},-\mathrm{CH}-$ $\mathrm{OH}-)$.

FT-IR (selected bands, $\mathrm{cm}^{-1}$ ): $1658 \nu$ (amide I), 1537 $\nu$ (amide II), $1201 \nu_{\text {as }}\left(\mathrm{SO}_{3}\right), 1040 \nu_{\mathrm{s}}\left(\mathrm{SO}_{3}\right)$.

UV-vis: absorbance bands in trifluoroethanol $\max =260$, 294, and $444 \mathrm{~nm}$; absorbance bands in water $\lambda_{\max }=260,297$, and $447 \mathrm{~nm}$. Photoluminescence: emission maximum in trifluoroethanol $\lambda_{\mathrm{PL}}=537 \mathrm{~nm}$, in water $\lambda_{\mathrm{PL}}=546 \mathrm{~nm}$.
Synthesis of poly(4-((3-methacrylamidopropyl)dimethylammonio)butane-1-sulfonate), poly(SBP). In a typical procedure, $\quad 4$-((3-methacrylamidopropyl)dimethylammonio) butane-1-sulfonate (SBP, $\left.5.0 \mathrm{~g}, 1.6 \times 10^{-2} \mathrm{~mol}\right),(R)-2-(6-(\mathrm{di}-$ methylamino)-1,3-dioxo-1 $H$-benzo[de]isoquinolin-2(3H)-yl)ethyl 4-cyano-4-(((phenethylthio)carbonothioyl)thio)pentanoate (CTA, $0.1 \mathrm{~g}, 1.6 \times 10^{-4} \mathrm{~mol}$ ), and 4,4'-azobis(4-cyanopentanoic acid) (V501, $0.009 \mathrm{~g}, 3 \times 10^{-5} \mathrm{~mol}$ ) are dissolved in trifluoroethanol $(9 \mathrm{ml})$. After purging with $\mathrm{N}_{2}$ for $30 \mathrm{~min}$, the yellow solution is polymerised at $75{ }^{\circ} \mathrm{C}$ for $18 \mathrm{~h}$. Then the mixture is cooled and precipitated into methanol (repeated 3 times). The polymer is isolated and dried in vacuo. Homopolymer polySBP is obtained as a hygroscopic, amorphous yellow solid (yield $3.1 \mathrm{~g}, 62 \%)$.

The individual samples are named $\operatorname{polySBP}_{n}$, with $n$ being the number average degree of polymerisation that was theoretically calculated (see Table 2).

${ }^{1} \mathrm{H}$ NMR $\left(300 \mathrm{MHz}\right.$, in dilute aqueous $\mathrm{NaCl}\left(0.9 \mathrm{~g} \mathrm{~L}^{-1}\right)$ in $\left.\mathrm{D}_{2} \mathrm{O}, 298 \mathrm{~K}\right): \delta(\mathrm{ppm})=0.6-1.2\left(\right.$ broad $5 \mathrm{H},-\mathrm{CH}_{3}$ and $-\mathrm{CH}_{2}-\mathrm{on} /$ in backbone), $1.6-2.1\left(6 \mathrm{H},-\mathrm{CH}_{2}-\mathrm{C}-\mathrm{N}^{+}-\mathrm{C}-\mathrm{CH}_{2}-\mathrm{CH}_{2}-\right), 2.8-3.0$ $\left(2 \mathrm{H},-\mathrm{CH}_{2}-\mathrm{SO}_{3}\right), 3.0-3.1\left(6 \mathrm{H},>\mathrm{N}^{+}\left(\mathrm{CH}_{3}\right)_{2}, 3.2-3.4\left(6 \mathrm{H},-\mathrm{CH}_{2}-\right.\right.$ $\left.\mathrm{N}^{+}-\mathrm{CH}_{2^{-}}, \mathrm{CON}-\mathrm{CH}_{2}^{-}\right)$.

FT-IR (selected bands, $\mathrm{cm}^{-1}$ ): $3446 \nu(\mathrm{NH}), 1645 \nu$ (amide I), $1539 \nu$ (amide II), $1195 \nu_{\text {as }}\left(\mathrm{SO}_{3}\right)$, and $1043 \nu_{\mathrm{s}}\left(\mathrm{SO}_{3}\right)$.

UV-vis: absorbance bands in trifluoroethanol $\lambda_{\max }=262$, 299, and $444 \mathrm{~nm}$; absorbance bands in water $\lambda_{\max }=259,298$, and $446 \mathrm{~nm}$. Photoluminescence: emission maximum in trifluoroethanol $\lambda_{\mathrm{PL}}=537 \mathrm{~nm}$, in water $\lambda_{\mathrm{PL}}=546 \mathrm{~nm}$.

\section{Methods}

Elemental analysis was carried out using a Vario ELIII microanalyzer (Elementar Analysensysteme, Germany). High resolution mass spectra (HR-MS) were recorded with a GC/MS-system Trace DSQII (Thermo Scientific). Infrared spectra were recorded from $\mathrm{KBr}$ pellets using a FT-IR spectrometer IFS 66/s (Bruker). Ultraviolet-visible (UV-vis) absorption spectra were recorded by using a UV/Vis/NIR Spectrometer Lambda instrument (Perkin Elmer). Photoluminescence spectra are recorded by using a Perkin Elmer Luminescence Spectrometer LS 50 B.

${ }^{1} \mathrm{H}$ and ${ }^{13} \mathrm{C}$ nuclear magnetic resonance (NMR) spectra, ${ }^{1} \mathrm{H}-{ }^{1} \mathrm{H}$-Correlation Spectra (COSY), and ${ }^{1} \mathrm{H}^{-13} \mathrm{C}-$ Heteronuclear Multiple Quantum Coherence spectra (HMQC) were recorded with a Bruker Avance 300 spectrometer $(300 \mathrm{MHz})$ at ambient temperature in deuterated water. The residual proton signal of the solvent was set to $4.78 \mathrm{ppm}$. Molar masses were determined by end group analysis, comparing the integrals of signals characteristic of the $R$ or $Z$ groups, respectively, with the integrals of the signals for the constitutional repeat unit. ${ }^{14}$

Theoretically expected number average molar masses $M_{\mathrm{n}}^{\text {theo }}$ are calculated according to eqn (1):

$$
M_{\mathrm{n}}^{\text {theo }}=\frac{\text { conversion } \times M_{\mathrm{CRU}} \times c_{\mathrm{M}}}{c_{\mathrm{CTA}}}+M_{\mathrm{CTA}}
$$

where $M_{\mathrm{CRU}}$ is the molar mass of the constitutional repeat unit, $M_{\text {CTA }}$ is the molar mass of the RAFT agent, $c_{\mathrm{M}}$ is the molar concentration of the monomer, and $c_{\mathrm{CTA}}$ is the molar 
concentration of the RAFT agent. Monomer conversions were determined from the ${ }^{1} \mathrm{H}$ NMR spectra of the crude polymerisation mixtures, by comparing the combined integral of the residual two olefinic proton signals to the integral of the signal of the methylammonium group.

Cloud points were determined by turbidimetry using a Varian Cary 50 Scan UV-Visible Spectrometer, equipped with a single cell Peltier thermostated cell holder, using $1 \mathrm{~cm} \times 1 \mathrm{~cm}$ quartz cuvettes. Aqueous polymer solutions with a concentration of $50 \mathrm{~g} \mathrm{~L}^{-1}$ were prepared in $\mathrm{D}_{2} \mathrm{O}$ or in Millipore water. Measurements were performed at a wavelength of $800 \mathrm{~nm}$ and with heating and cooling rates of $0.5 \mathrm{~K} \mathrm{~min}^{-1}$. The cloud point was taken as the temperature where the normalised transmittance of the optically clear solution in the cooling runs started to decrease notably (i.e., reduction by $2 \%$ ).

\section{Results and discussion}

Monomers 2-hydroxy-3-((3-methacrylamidopropyl)dimethylammonio)propane-1-sulfonate (SHPP) and 4-((3-methacrylamidopropyl)dimethylammonio)butane-1-sulfonate (SBP) (Fig. 1) were prepared by straightforward alkylation of a commercially available tertiary amine precursor. In the case of SBP, alkylation was achieved by the ring opening reaction with butanesultone in a aprotic, highly polar solvent acetonitrile, following a classical scheme. ${ }^{21,25-27}$ Despite the lower reactivity of butanesultone ${ }^{21}$ compared to propanesultone and the low reaction temperature, the particular procedure with an extended reaction time resulted in close to quantitative yield. The ${ }^{1} \mathrm{H}-\mathrm{NMR}$ characterisation of SBP (Fig. 2) agrees precisely with the most recently published data. ${ }^{21}$ In the case of SHPP, alkylation was performed with the commercially available sodium 3-chloro-2-hydroxy-1-propane sulfonate. While circumventing the use of the rather potent sultone cancerogenes, the lower reactivity of the chloride required higher reaction temperatures to achieve satisfactory yields. Moreover, aqueous ethanol which may lead to side reactions, had to be employed as a reaction medium due to the low solubility of the ionic alkylating agent in aprotic solvents, such as acetonitrile which are a priori more inert. Furthermore, the formation of sodium chloride as the byproduct, which may tenaciously stick to the sulfobetaine moiety, required the purification of SHPP with a mixed bed ion exchanger, to obtain a monomer free of inorganic salt contamination. ${ }^{28,29}$ Though reference data are missing, the ${ }^{1}$ H-NMR spectra of SHPP (Fig. 2) fit well with the typical features of related sulfobetaine monomers. ${ }^{30}$

As reported for other sulfobetaine monomers, ${ }^{3,14,31}$ radical polymerisation of both SHPP and SBP proceeded homogeneously and smoothly in trifluoroethanol. In particular, the polymers were synthesised by the RAFT (reversible additionfragmentation chain transfer) ${ }^{32,33}$ technique (Table 1). This enables not only the preparation of polymers with predefined molar masses and low polymer dispersity, but also the incorporation of two different well-defined end groups. Using the RAFT agent trithiocarbonate CTA that is functionalised with a naphthalimide dye on its $R$-group, we attached a fluorophore permanently to the polymers. Beyond facilitating the<smiles>C=C(C)C(=O)NCCC[N+](C)(C)CCCS(=O)(=O)[O-]</smiles>

\section{SPP}
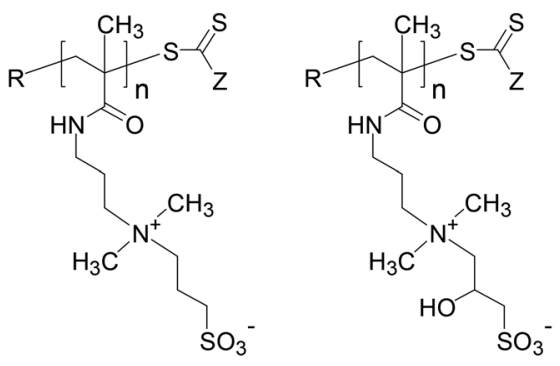

polySHPP $_{n}$

polySPP $_{n}$<smiles>C=C(C)C(=O)NCCC[N+](C)(C)CCCCS(=O)(=O)O</smiles><smiles>CCCN1C(=O)c2cccc3c(N(C)C)ccc(c23)C1=O</smiles><smiles>CCSC(C)(C)CCC(=O)O</smiles>

CTA

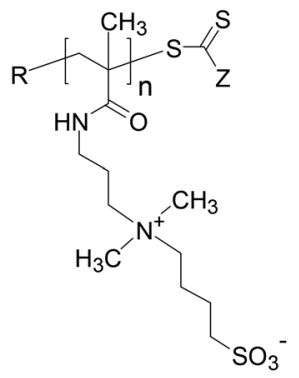

polySBP $_{n}$

Fig. 1 Chemical formulae of the monomers SPP, SHPP, and SBP, the fluorophore labeled RAFT agent CTA and the derived polymers. 

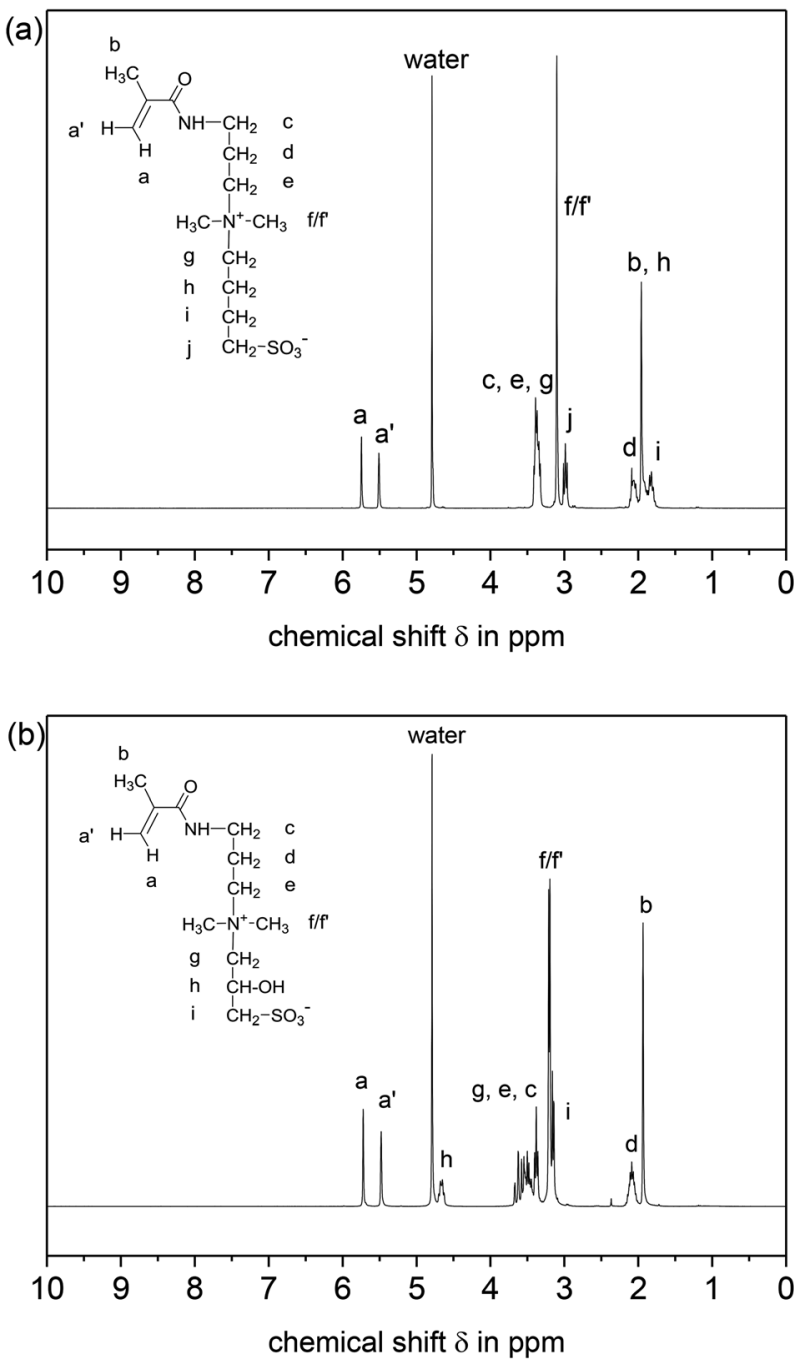

Fig. $2{ }^{1} \mathrm{H}$ NMR spectra of monomers (a) SBP, and (b) SHPP in $\mathrm{D}_{2} \mathrm{O}$. Signals were assigned via ${ }^{1} \mathrm{H}-{ }^{1} \mathrm{H}-\mathrm{COSY}$ and ${ }^{1} \mathrm{H}-{ }^{13} \mathrm{C}-\mathrm{HMQC}$ experiments.

notoriously complicated molecular analysis of polyzwitterions, ${ }^{14,34,35}$ these labeled polymers can be easily tracked by fluorescence spectroscopy or microscopy techniques in model studies. Inevitably, the molar masses of the coloured, fluorescent polymers obtained decrease with increasing amounts of CTA engaged and incorporated (Tables 1 and 2).

The ${ }^{1} \mathrm{H}$ NMR characterisation of polySHPP and polySBP does not reveal anything unusual concerning the polymers' molecular structure, showing the typical signal broadening (Fig. 3). The spectra show the presence of end groups derived from the RAFT agent, and the absence of a residual monomer. The signals between 0.5 and $1.2 \mathrm{ppm}$, which originate from the methyl group attached to the polymer backbone, provide information on the polymer tacticity. Their integration indicates identical tacticities for all samples, with about $60-65 \%$ of syndiotactic, $30-35 \%$ of atactic and $<5 \%$ of isotactic triads. This finding corresponds to the typical situation encountered in the free radical polymerisation of methacrylates at a chosen temperature, in spite of the use of a fluorinated alcohol as a reaction medium. ${ }^{36,37}$

End-group analysis of the polymers via the intense absorbance band of the naphthalimide chromophore attached to the $R$-group is advantageous compared to the use of the rather weak ${ }^{1} \mathrm{H}$ NMR signals of the aromatic end groups (Fig. 3). This is particularly helpful for high molar masses, when the ${ }^{1} \mathrm{H}$ NMR signals get too small to be useful. However, due to the marked solvatochromism of the chromophore, not only the position of the absorbance bands, but also the extinction coefficient may vary notably with the polarity of the environment. Assuming the same extinction coefficient as derived for polySPP in trifluoroethanol, ${ }^{14}$ the calculated molar masses are in excellent agreement with the theoretically expected values (Table 2), as is typical for a well-behaved RAFT polymerisation. End-group analysis of the polymers using ${ }^{1} \mathrm{H}$ NMR also shows good agreement between the theoretically expected and experimentally found values, but the precision is limited due to the low signal intensities. A comparison of the relative intensities of the signals due to the $R$ - and the $Z$-groups of the RAFT agent further suggests that the active end groups were mostly retained, although some losses may occur.

Concerning thermal properties, polySHPP and polySBP behave very closely to the reference polymer polySPP. While thermogravimetric analysis (TGA) shows the onset of decompo-

Table 1 Reaction conditions for the RAFT solution polymerisation of SBP and SHPP in trifluoroethanol at $75^{\circ} \mathrm{C}$, using initiator V501. Monomer concentration was $30 \mathrm{wt} \%$

\begin{tabular}{|c|c|c|c|c|c|c|}
\hline Entry & Sample & $\begin{array}{l}\text { Molar ratio } \\
\text { Monomer: CTA: V501 }\end{array}$ & $m_{\text {monomer }}[\mathrm{g}]$ & $m_{\mathrm{CTA}}[\mathrm{g}]$ & $m_{\mathrm{V} 501}[\mathrm{~g}]$ & $t[\mathrm{~h}]$ \\
\hline 1 & polySBP $_{40}$ & $100: 1: 0.2$ & 5.0 & 0.100 & 0.009 & 0.75 \\
\hline 3 & polySBP $_{80}$ & $100: 1: 0.2$ & 5.0 & 0.100 & 0.009 & 2.50 \\
\hline 4 & polySBP $_{245}$ & $300: 1: 0.2$ & 5.0 & 0.030 & 0.003 & 7.50 \\
\hline 5 & polySBP $_{425}$ & $600: 1: 0.2$ & 5.0 & 0.017 & 0.002 & 15.0 \\
\hline 6 & polySHPP $_{70}$ & $100: 1: 0.2$ & 1.6 & 0.030 & 0.003 & 3.00 \\
\hline 9 & polySHPP $_{235}$ & $300: 1: 0.2$ & 1.0 & 0.007 & 0.001 & 9.00 \\
\hline 10 & polySHPP $_{460}$ & $600: 1: 0.2$ & 1.0 & 0.003 & 0.001 & 18.0 \\
\hline 11 & polySHPP $_{505}$ & $600: 1: 0.2$ & 1.0 & 0.003 & 0.001 & 18.0 \\
\hline
\end{tabular}


Table 2 Molecular characterisation data of the synthesised polymers. Monomer conversions were determined by ${ }^{1} \mathrm{H}$ NMR analysis of the crude reaction mixtures

\begin{tabular}{|c|c|c|c|c|c|c|}
\hline \multirow[b]{2}{*}{ Sample } & \multirow[b]{2}{*}{$\begin{array}{l}\text { Conversion } \\
{[\%]}\end{array}$} & \multicolumn{4}{|c|}{$M_{\mathrm{n}}\left[\mathrm{kg} \mathrm{mol}{ }^{-1}\right]$} & \multirow[b]{2}{*}{$\begin{array}{l}\text { Ratio } Z / R \\
\text { (NMR) }\end{array}$} \\
\hline & & $\begin{array}{l}\text { Theoretical } \\
\left(M_{\mathrm{n}}^{\text {theo }}\right)\end{array}$ & $\begin{array}{l}\text { By }{ }^{1} \mathrm{H} \text { NMR } \\
\text { (via } Z \text {-group) }\end{array}$ & $\begin{array}{l}\text { By }{ }^{1} \mathrm{H} \text { NMR } \\
\text { (via } R \text {-group) }\end{array}$ & $\begin{array}{l}\text { By UV-vis } \\
\text { (via } R \text {-group) }^{a}\end{array}$ & \\
\hline polySBP $_{40}$ & 40 & 13 & 22 & 13 & 18 & $\sim 0.6$ \\
\hline polySBP $_{50}$ & 50 & 16 & 24 & 17 & 23 & $\sim 0.7$ \\
\hline polySBP $_{80}$ & 80 & 25 & 38 & 30 & 23 & $\sim 0.8$ \\
\hline polySBP $_{245}$ & 81 & 71 & n.d. ${ }^{b}$ & n.d. ${ }^{b}$ & 68 & - \\
\hline polySBP $_{425}$ & 71 & 131 & n.d. ${ }^{b}$ & n.d. ${ }^{b}$ & 122 & - \\
\hline polySHPP $_{70}$ & 70 & 23 & 26 & 24 & 24 & $\sim 0.9$ \\
\hline polySHPP $_{80}$ & 80 & 26 & 30 & 27 & 27 & $\sim 0.9$ \\
\hline polySHPP $_{115}$ & 19 & 35 & 43 & 36 & 36 & $\sim 0.9$ \\
\hline polySHPP $_{235}$ & 78 & 73 & n.d. ${ }^{b}$ & n.d. ${ }^{b}$ & 79 & - \\
\hline polySHPP $_{460}$ & 76 & 142 & n.d. ${ }^{b}$ & n.d. ${ }^{b}$ & 158 & - \\
\hline polySHPP $_{505}$ & 84 & 156 & n.d. ${ }^{b}$ & n.d. ${ }^{b}$ & 175 & - \\
\hline
\end{tabular}

${ }^{a}$ Calculated from the maximum absorbance in trifluoroethanol, using the extinction coefficient of $\varepsilon=1.0 \times 10^{4} \mathrm{~L} \mathrm{~mol}{ }^{-1} \mathrm{~cm}^{-1}$ derived from trifluoroethanol for the chromophore incorporated in polySPP. ${ }^{14 b}$ Signal intensity too weak to allow reliable integration.
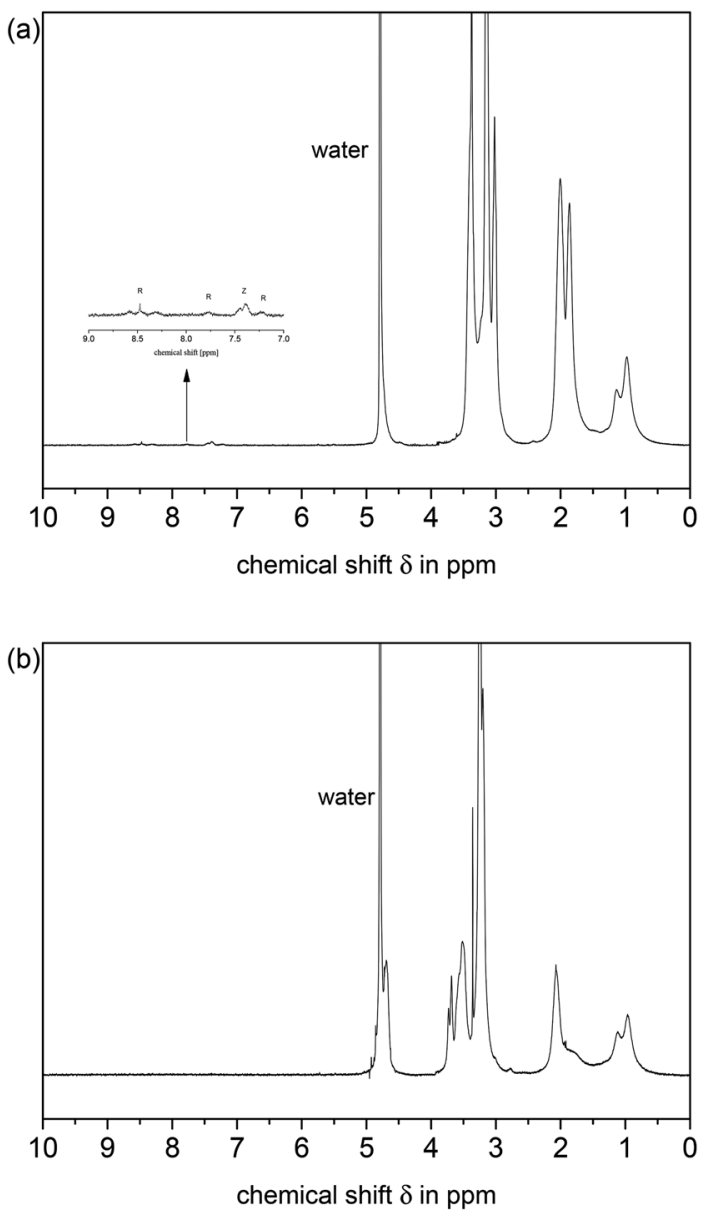

Fig. $3{ }^{1} \mathrm{H}$ NMR spectra of polymers (a) polySBP, and (b) polySHPP in $D_{2} \mathrm{O}$. The zoom-in image shows the signals of the end groups $(R=$ $R$-group, and $Z$ = Z-group) between 7 and 9 ppm.

sition accompanied by mass loss at about $270{ }^{\circ} \mathrm{C}$ for polySPP and polySHPP, the onset is found at about $300{ }^{\circ} \mathrm{C}$ in the case of polySBP. Differential scanning calorimetry (DSC) shows no thermal transition for any of the polymers before degradation starts, in agreement with reports on many poly(sulfobetaine)s. ${ }^{27,38}$

Similar to the behaviour of the reference polySPP, both polySHPP and polySBP are insoluble in aprotic solvents, such as chloroform, acetone, acetonitrile, DMSO or DMF, and also in many protic solvents, such as methanol and ethanol. They dissolve however easily in trifluoroethanol (TFE), hexafluoroisopropanol (HFIP), formamide or brine. ${ }^{22,26,39}$

Solubility in water as well as in deuterated water is complex, showing a miscibility gap at lower temperatures, with a phase transition of the UCST-type (Table 3). The phase separation temperatures depend not only sensitively on the precise chemical structure of the polyzwitterions, but also on their concentration and molar mass (Fig. 4 and 5). In the turbidimetric studies of solutions of polySHPP and polySBP in both $\mathrm{H}_{2} \mathrm{O}$ and $\mathrm{D}_{2} \mathrm{O}$, the clouding transitions were all sharp and curves were highly reproducible (see the ESI $\dagger$ ). The hysteresis between the cloud points for heating and cooling runs was marginal $\left(\leq 1{ }^{\circ} \mathrm{C}\right)$. Accordingly, the binodal and spinodal lines of the polySHPP/water and polySBP/water phase diagrams coincide virtually. Table 3 summarises the derived cloud points. First of all, we see that the cloud points are much higher for polySBP than those for polySHPP, as anticipated. While the polySHPP sample with the lowest molar mass is fully soluble in $\mathrm{H}_{2} \mathrm{O}$ without any cloud point, the polySBP samples with the highest molar masses are no more soluble in $\mathrm{H}_{2} \mathrm{O}$ at all. Still, as a common feature, the cloud points increase monotonously with increasing molar mass for both polymers in $\mathrm{H}_{2} \mathrm{O}$ as well as in $\mathrm{D}_{2} \mathrm{O}$ (Fig. 4). Also, the cloud points increase with increasing concentration at least up to $50 \mathrm{~g} \mathrm{~L}^{-1}$ (Fig. 5), apparently approaching asymptotically a maximum value. As already found for polySPP, the cloud point of a given sample is markedly higher in heavy water $\left(\mathrm{D}_{2} \mathrm{O}\right)$ than in normal water $\left(\mathrm{H}_{2} \mathrm{O}\right)$. The differences are in the range of about $6^{\circ} \mathrm{C}$ in the case of polySBP, which corresponds closely to the behaviour of polySPP,${ }^{14}$ and of about $15{ }^{\circ} \mathrm{C}$ in the case of polySHPP. This 
Table 3 UCST-type cloud points of $5 \mathrm{wt} \%$ aqueous solutions of the polyzwitterion series polySBP$n$ and polySHPP

\begin{tabular}{llcr}
\hline & & \multicolumn{2}{c}{ Cloud point $\left[{ }^{\circ} \mathrm{C}\right]$} \\
\cline { 3 - 4 } Entry & Sample & In $\mathrm{H}_{2} \mathrm{O}$ & In $\mathrm{D}_{2} \mathrm{O}$ \\
\hline 1 & polySBP $_{\mathbf{4 0}}$ & 60 & 66 \\
2 & polySBP $_{\mathbf{5 0}}$ & 67 & 76 \\
3 & polySBP $_{\mathbf{8 0}}$ & 74 & 78 \\
4 & polySBP $_{\mathbf{2 4 5}}$ & $>100$ & $>100$ \\
5 & polySBP $_{\mathbf{4 2 5}}$ & $>100$ & $>100$ \\
6 & polySHPP $_{\mathbf{7 0}}$ & $<0$ & 17 \\
7 & polySHPP $_{\mathbf{8 0}}$ & 6 & 18 \\
8 & polySHPP $_{\mathbf{1 1 5}}$ & 10 & 30 \\
9 & polySHPP $_{\mathbf{2 3 5}}$ & 13 & 38 \\
10 & polySHPP $_{\mathbf{4 6 0}}$ & 22 & 51 \\
11 & polySHPP $_{\mathbf{5 0 5}}$ & 34 &
\end{tabular}

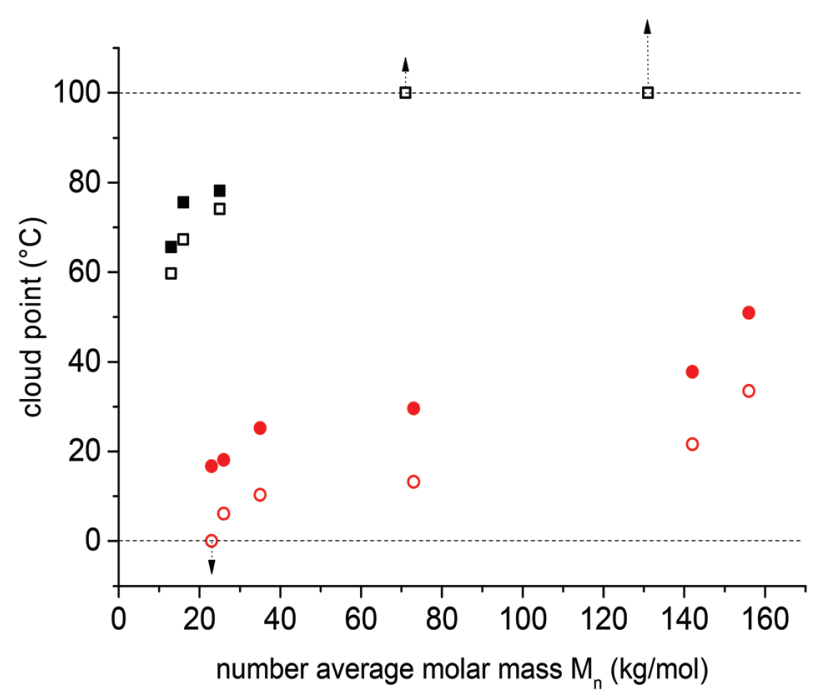

Fig. 4 Evolution of cloud points in $5 \mathrm{wt} \%$ aqueous solutions with increasing molar mass of polySBP${ }_{n}:(\square)=$ in $\mathrm{H}_{2} \mathrm{O},(\square)=\mathrm{D}_{2} \mathrm{O}$; and polySHPP ${ }_{n}$ : (O) $=$ in $\mathrm{H}_{2} \mathrm{O},(\bullet)=\mathrm{D}_{2} \mathrm{O}$.

pronounced isotope effect exceeds by far the analogous effect for the LCST-type coil-to-globule transition of, e.g., poly( $\mathrm{N}$-isopropylacrylamide), that is in the range of $1^{\circ} \mathrm{C}$ at most. ${ }^{40,41}$ The marked isotope effect implies that the results of studies of these polyzwitterions performed in $\mathrm{D}_{2} \mathrm{O}$, as e.g. is characteristic of many ${ }^{1} \mathrm{H}$ NMR or neutron scattering studies, may not be directly transferable to their behaviour in "normal" aqueous systems.

The reasons for the strong isotope effect are not clear at present. Still, the strength of the observed effect as well as the finding that effects are similarly strong for the sulfobetaine homologues polySBP and polySPP, while they are much stronger for the analogue polySHPP bearing an additional hydroxyl group, suggest a major role of hydrogen bonding for the effective hydration of the polyzwitterions. Interestingly, similarly marked hydrogen-deuterium isotope effects were reported for blends of poly(acrylamide) and poly(acrylic acid), or copolymers of acrylamide and acrylonitrile also, both showing UCST-type behaviour in aqueous solution. ${ }^{42,43}$ Cooperative complementary hydrogen bonding between the different polymer segments has been invoked as an explanation, which obviously cannot apply in our case. In any case, a major role of hydrogen bonding to provoke the strong isotope effects is also consistent with the finding that the cloud points of the polySHPP series (Table 3) are the same or even slightly higher than the ones of the polySPP series, ${ }^{14}$ although a priori, the additional hydrophilic hydroxyl group would have been expected to lower the cloud points somewhat. In contrast, the cloud points of the polySBP series are much higher than those for polySPP, as may have been intuitively anticipated due to the longer, and thus more hydrophobic alkyl spacer group between the cationic and the anionic groups. The latter finding is in full agreement with a recent report on the behaviour of poly(acrylamide) analogs of polySPP and polySBP. ${ }^{21}$

The UCST-type phase transition behaviour of polyzwitterions in aqueous media is known to be very sensitive to the presence of additives, in particular of inorganic salts. Not only the amount or the ionic strength of the added salt is important, but also the precise nature of the ions added, in particular the nature of the anion. ${ }^{14-16,22,39}$ Therefore, we also studied the influence of selected salts on the cloud points of polySHPP and polySBP dissolved in $\mathrm{H}_{2} \mathrm{O}$ (Fig. 6).

When adding salts to aqueous solutions of polySHPP (Fig. 6a), the cloud points evolve in many respects with a similar pattern as observed for its analog polySPP ${ }^{14}$ and other polyzwitterions bearing the ammoniopropanesulfonate moiety. ${ }^{15,16}$ Already small amounts of a salt have a big impact, and their efficiencies vary markedly with the nature of the anion. Still, the addition of salts does not lead automatically to a general "salting-in" effect as is often assumed. Instead, the cloud points increase first, when small amounts of salts are added, and pass through a maximum, before they decrease finally to below freezing point when salt concentrations reach the $100 \mathrm{mM}$ range. This remarkable effect might have been missed in the past for other polymeric ammoniopropanesulfonates, because these polymers tend to adsorb strongly inorganic salts up to stoichiometric amounts, once they have been exposed to them. ${ }^{38,44}$ However, the absence of contaminating inorganic salts, which possibly accumulate during the synthesis and handling of such polymers, has been rarely verified before studying cloud points. In fact, small contaminations by inorganic salts might be the reason for at least some of the apparently conflicting data on the phase transition temperatures of certain poly(sulfobetaine)s such as polySPE in the literature. ${ }^{15,16,45,46}$

A striking feature of the salt effects observed for the solutions of polySHPP is however, that the effectiveness of the anions correlates inversely with the empirical Hofmeister series, ${ }^{47-49}$ namely, salting-in effectiveness increases in the order $\mathrm{Br}^{-}<\mathrm{Cl}^{-}<\mathrm{SO}_{4}{ }^{2-}$. This behaviour is opposite to all previous findings for poly(sulfobetaine)s, such as polySPP $^{14}$ and polySPE, ${ }^{15,24,39,50}$ or their analogues. ${ }^{16,51,52}$ The reasons 
(a)

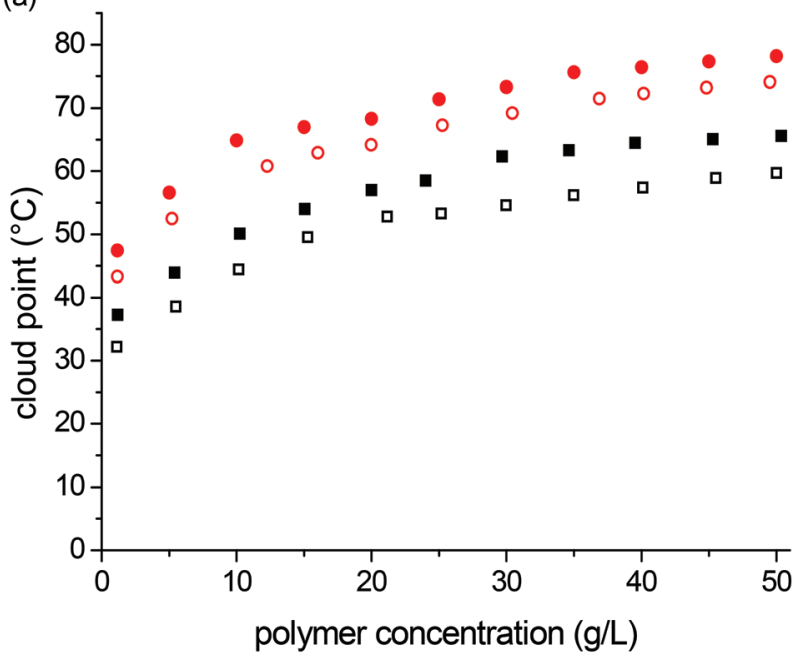

(b)

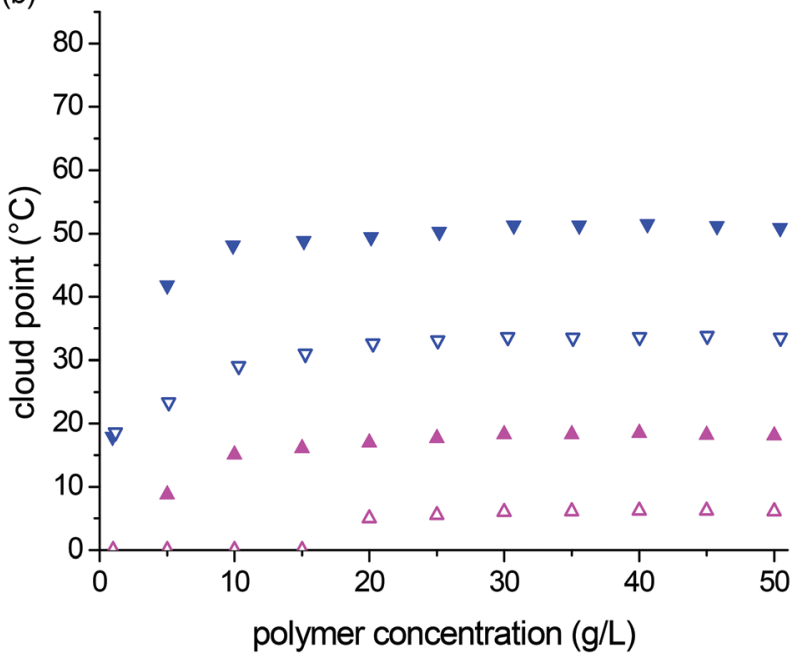

Fig. 5 Concentration dependent evolution of cloud points in aqueous solution of (a) polySBP 40 : $(\square)=$ in $\mathrm{H}_{2} \mathrm{O},(\square)=\mathrm{D}_{2} \mathrm{O}$; polySBP $\mathrm{Bo}_{80}$ : $(\mathrm{O})=$ in $\mathrm{H}_{2} \mathrm{O},(\bullet)=\mathrm{D}_{2} \mathrm{O}$ and of (b) polySHPP ${ }_{80}:(\triangle)=\mathrm{H}_{2} \mathrm{O},(\boldsymbol{\Delta})=\mathrm{D}_{2} \mathrm{O}$; polySHPP ${ }_{505}:(\nabla)=\mathrm{H}_{2} \mathrm{O},(\nabla)=\mathrm{D}_{2} \mathrm{O}$.

are not clear at present, but obviously, the hydroxyl group in the spacer separating the ammonium and the sulfonate moieties must affect the electrostatic interactions between the ionic groups. Possibly, an intramolecular hydrogen bond is formed between the hydroxyl and the sulfonate moieties, thus changing the ability of the latter to interact with the ammonium group.

Interestingly, the cloud points evolve even more differently for aqueous solutions of polySBP in comparison with polySPP when a salt is added (Fig. 6b). Again small amounts of a salt make a big impact, and their efficiencies increase in the Hofmeister anion series as $\mathrm{SO}_{4}{ }^{2-}<\mathrm{Cl}^{-}<\mathrm{Br}^{-}$. However, the cloud points decrease continuously from the very first addition, when $\mathrm{NaCl}$ or $\mathrm{NaBr}$ are added, and do not pass through a maximum. Increasing concentrations of $\mathrm{Na}_{2} \mathrm{SO}_{4}$ or $\left(\mathrm{NH}_{4}\right)_{2} \mathrm{SO}_{4}$ decrease the cloud point first, then make it pass
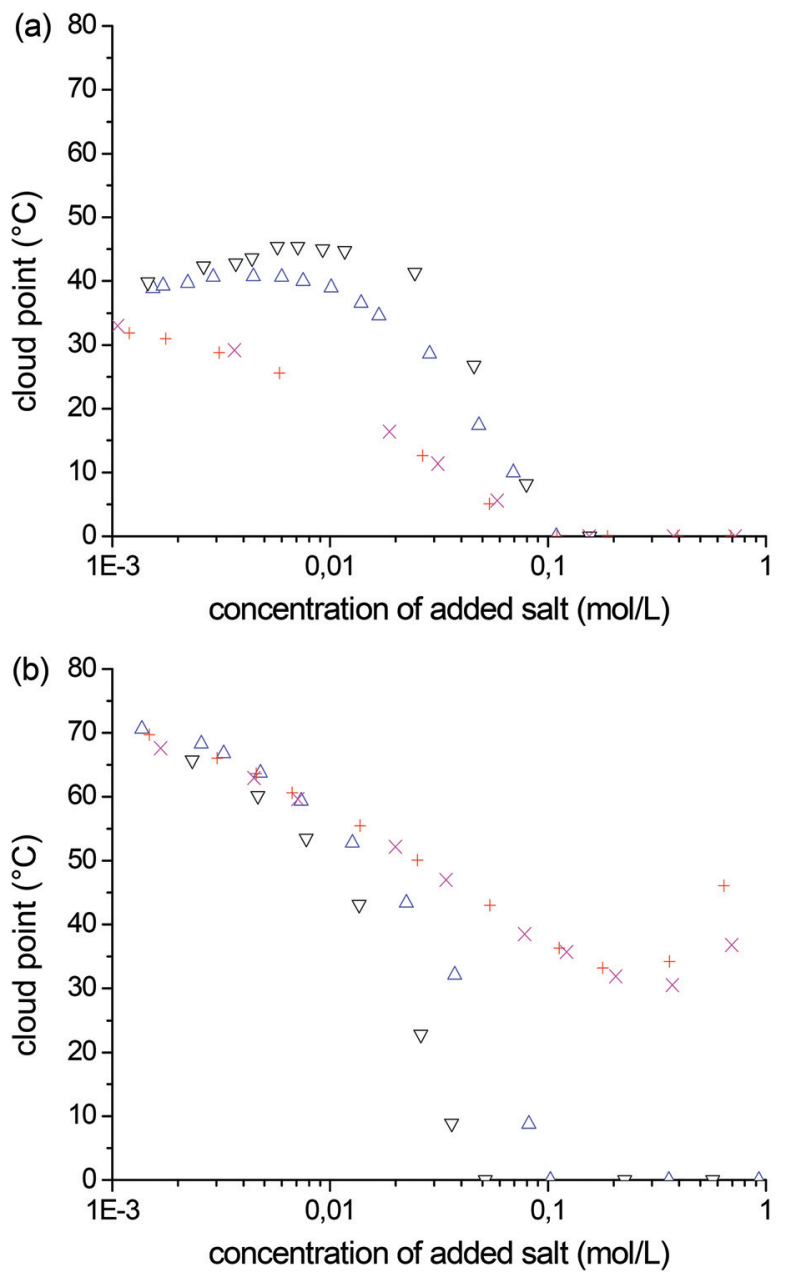

Fig. 6 Evolution of the cloud points in 5 wt\% aqueous solutions $\left(\mathrm{H}_{2} \mathrm{O}\right)$ containing inorganic salts of poly(sulfobetaine)s polySHPP ${ }_{505}$ (a) and polySBP 80 (b): $(\triangle)=\mathrm{NaCl},(\nabla)=\mathrm{NaBr},(+)=\mathrm{Na}_{2} \mathrm{SO}_{4},(\mathrm{x})=\left(\mathrm{NH}_{4}\right)_{2} \mathrm{SO}_{4}$.

through a minimum in the lower $100 \mathrm{mM}$ range, before they make the cloud point slowly rise again above about $0.3 \mathrm{M}$. Such a minimum of the cloud point at intermediate to high concentrations of sulfates is also observed for polySPP (see the ESI $\dagger$ ).

At present, we cannot offer a satisfactory explanation for this puzzling behaviour. In any case, it becomes clear that the effects of inorganic salts on polyzwitterions are complex. The interactions are not only sensitive to the precise nature of the ionic groups involved, but also to the detailed structure of the spacer group separating the cationic and the anionic moieties of the zwitterions. Importantly, we note that the chloride anion interacts rather effectively with all the poly(sulfobetaine)s studied here, so that their cloud points vanish in physiological $\mathrm{NaCl}$ solution $\left(9 \mathrm{~g} \mathrm{~L}^{-1}, 0.15 \mathrm{M}\right)$. Moreover, for selected examples, we compared the effect of a given concentration of an added salt on the cloud points in $\mathrm{H}_{2} \mathrm{O}$ and $\mathrm{D}_{2} \mathrm{O}$. We found in all cases that the cloud point is shifted by nearly the same value in either solvent. 


\section{Conclusions}

Zwitterionic monomers 2-hydroxy-3-((3-methacrylamidopropyl) dimethylammonio)propane-1-sulfonate (SHPP) and 4-((3methacrylamidopropyl)dimethylammonio)butane-1-sulfonate (SBP) were synthesised in good to excellent yields. They could be smoothly polymerised by reversible addition-fragmentation chain transfer polymerisation (RAFT) in a homogeneous solution in trifluoroethanol, without affecting the tacticity compared to the standard radical polymerisation process. The RAFT method enables facile incorporation of functional end groups, such as those bearing a fluorescent label, into the polymers.

Both polySHPP and polySBP are thermo-responsive in aqueous solution, exhibiting a UCST-type coil-to-globule phase transition, depending on the polyzwitterions' concentration and molar mass. The chemical structure of the spacer group separating the ammonium and the sulfonate groups strongly affects the phase transition temperature, too. The effects seem, however, difficult to predict so far. The cloud point of polySBP is much higher than the one of the homologue polysPP of a comparable molar mass, as anticipated from a simple analysis of the hydrophilic and hydrophobic groups contained. In contrast, the cloud point of polySHPP is similar, or even slightly higher than the one of the analogous polySPP, despite the incorporation of an additional hydrophilic hydroxyl group into the spacer. These findings suggest a rather complex influence of the spacer group on the hydrophilicity of the zwitterionic moiety. It is noteworthy that the cloud points in $\mathrm{H}_{2} \mathrm{O}$ and $\mathrm{D}_{2} \mathrm{O}$ differ substantially for both polymer series, in which the differences are considerably more pronounced for polySHPP. This must be taken into account for interpreting studies of such polyzwitterions using deuterated solvents.

In agreement with the well-known anti-polyelectrolyte effect reported for other polyzwitterions, including polySPP, the solubility of both polySHPP and polySBP in water is very sensitive to the addition of inorganic salts. The effectivity of salts in modulating the cloud point can be correlated with the empirical Hofmeister series. Still, the cloud points of the three polymers show characteristic differences in their detailed behaviour upon salt addition. The cloud point of polySHPP passes through a maximum with increasing amounts of salt added, similar to the behaviour of polySPP, but the anion effects on polySHPP correlate inversely with the Hofmeister series. In contrast, the cloud points of polySBP decrease monotonously when sodium halogenides are added, but pass through a minimum in the case of added sulfates. These salt effects await understanding, as they will affect not only the use of such polymers in responsive systems, but also in all potential applications in biological or environmental systems that inherently contain low molar mass electrolytes. In any case, our findings show that apparently small variations of the spacer group separating the anionic and the cationic moieties of sulfobetaines are a surprisingly effective structural parameter for modulating the phase transition temperature of these polyzwitterions in specific aqueous environments.

\section{Acknowledgements}

The authors thank C. M. Papadakis and P. Müller-Buschbaum (both Physics Dept., TU München) for stimulating discussions. This work was supported by Deutsche Forschungsgemeinschaft (DFG) under Grant La611/11.

\section{References}

1 A. B. Lowe and C. L. McCormick, Chem. Rev., 2002, 102, 4177-4189.

2 S. Kudaibergenov, W. Jaeger and A. Laschewsky, $A d v$. Polym. Sci., 2006, 201, 157-224.

3 A. Laschewsky, Polymers, 2014, 6, 1544-1601.

4 D. W. Grainger, Nat. Biotechnol., 2013, 31, 507-509.

5 J. B. Schlenoff, Langmuir, 2014, 30, 9625-9636.

6 L. Mi and S. Jiang, Angew. Chem., Int. Ed., 2014, 53, 17461754.

7 S. Lowe, N. M. O’Brien-Simpson and L. A. Connal, Polym. Chem., 2015, 6, 198-212.

8 M. Arotçaréna, B. Heise, S. Ishaya and A. Laschewsky, J. Am. Chem. Soc., 2002, 124, 3787-3793.

9 J. V. M. Weaver, S. P. Armes and V. Bütün, Chem. Commun., 2002, 2122-2123.

10 Y. Maeda, H. Mochiduki and I. Ikeda, Macromol. Rapid Commun., 2004, 25, 1330-1334.

11 M. Mertoglu, S. Garnier, A. Laschewsky, K. Skrabania and J. Storsberg, Polymer, 2005, 46, 7726-7740.

12 J. D. Flores, X. Xu, N. J. Treat and C. L. McCormick, Macromolecules, 2009, 42, 4941-4945.

13 V. A. Vasantha, S. Jana, S. S.-C. Lee, C.-S. Lim, S. L.-M. Teo, A. Parthiban and J. G. Vancso, Polym. Chem., 2015, 6, 599606.

14 V. Hildebrand, A. Laschewsky and D. Zehm, J. Biomater. Sci., Polym. Ed., 2014, 25, 1602-1618.

15 D. N. Schulz, D. G. Peiffer, P. K. Agarwal, J. Larabee, J. J. Kaladas, L. Soni, B. Handwerker and R. T. Garner, Polymer, 1986, 27, 1734-1742.

16 P. Köberle, A. Laschewsky and T. D. Lomax, Makromol. Chem., Rapid Commun., 1991, 12, 427-433.

17 P. Mary and D. D. Bendejacq, J. Phys. Chem. B, 2008, 112, 2299-2310.

18 L. Sonnenschein and A. Seubert, Tetrahedron Lett., 2011, 52, 1101-1104.

19 P. Kasák, Z. Kroneková, I. Krupa and I. Lacík, Polymer, 2011, 52, 3011-3020.

20 D. Kratzer, L. Barner, C. Friedmann, S. Bräse and J. Lahann, Eur. J. Org. Chem., 2014, 8064-8071.

21 Y. Zhu, J.-M. Noy, A. B. Lowe and P. J. Roth, Polym. Chem., 2015, 6, 5705-5718.

22 J. Cardoso, R. Manrique, M. Albores-Velasco and A. Huanosta, J. Polym. Sci., Part B: Polym. Phys., 1997, 35, 479-488.

23 D. Bendejacq and C.-T. Vuong, (Rhodia Operations) PCT Pat., WO2010040813A1 (CAPLUS AN 2010:469298), 2010. 
24 P. Mary, D. D. Bendejacq, M.-P. Labeau and P. Dupuis, J. Phys. Chem. B, 2007, 111, 7767-7777.

25 V. M. Monroy Soto and J. C. Galin, Polymer, 1984, 25, 121128.

26 A. Laschewsky and I. Zerbe, Polymer, 1991, 32, 2070-2080.

27 P. Köberle, A. Laschewsky and D. van den Boogaard, Polymer, 1992, 33, 4029-4039.

28 Y. Chevalier, Y. Storet, S. Pourchet and P. Le Perchec, Langmuir, 1991, 7, 848-853.

29 P. Favresse and A. Laschewsky, Polymer, 2001, 42, 27552766.

30 A. Laschewsky, R. Touillaux, P. Hendlinger and A. Vierengel, Polymer, 1995, 36, 3045-3049.

31 B. Yu, A. B. Lowe and K. Ishihara, Biomacromolecules, 2009, 10, 950-958.

32 G. Moad, E. Rizzardo and S. H. Thang, Polymer, 2008, 49, 1079-1131.

33 Handbook of RAFT Polymerization, ed. C. Barner-Kowollik, Wiley-VCH, Weinheim, Germany, 2008.

34 M. Päch, D. Zehm, M. Lange, I. Dambowsky, J. Weiss and A. Laschewsky, J. Am. Chem. Soc., 2010, 132, 8757-8765.

35 K. Skrabania, A. Miasnikova, A. M. Bivigou-Koumba, D. Zehm and A. Laschewsky, Polym. Chem., 2011, 2, 20742083.

36 Y. Isobe, K. Yamada, T. Nakano and Y. Okamoto, Macromolecules, 1999, 32, 5979-5981.

37 Y. Miura, T. Satoh, A. Narumi, O. Nishizawa, Y. Okamoto and T. Kakuchi, Macromolecules, 2005, 38, 1041-1043.
38 P. Köberle and A. Laschewsky, Macromolecules, 1994, 27, 2165-2179.

39 V. M. Monroy Soto and J. C. Galin, Polymer, 1984, 25, 254262.

40 H. Mao, C. Li, Y. Zhang, S. Furyk, P. S. Cremer and D. E. Bergbreiter, Macromolecules, 2004, 37, 1031-1036.

41 M. J. A. Hore, B. Hammouda, Y. Li and H. Cheng, Macromolecules, 2013, 46, 7894-7901.

42 N. Endo, H. Shirota and K. Horie, Macromol. Rapid Commun., 2001, 22, 593-597.

43 L. Hou and P. Wu, Soft Matter, 2015, 11, 7059-7065.

44 P. Köberle and A. Laschewsky, Macromol. Symp., 1994, 88, 165-175.

45 A. B. Lowe, N. C. Billingham and S. P. Armes, Macromolecules, 1999, 32, 2141-2148.

46 H. Willcock, A. Lu, C. F. Hansell, E. Chapman, I. R. Collins and R. K. O'Reilly, Polym. Chem., 2014, 5, 1023-1030.

47 P. S. C. Yanjie Zhang, Curr. Opin. Chem. Biol., 2006, 10, 658-663.

48 P. Lo Nostro and B. W. Ninham, Chem. Rev., 2012, 112, 2286-2322.

49 A. Salis and B. W. Ninham, Chem. Soc. Rev., 2014, 43, 73587377.

50 Q. Yang and M. Ulbricht, Chem. Mater., 2012, 24, 2943-2951.

51 J. C. Salamone, W. Volksen, A. P. Olson and S. C. Israel, Polymer, 1978, 19, 1157-1162.

52 T. A. Wielema and J. B. F. N. Engberts, Eur. Polym. J., 1990, 26, 639-642. 